\title{
As vivências do PIBID: o que é bonito para você?
}

Lara Casarim Leite

Vanessa das Graças Pereira de Souza

Lucas Rieger de Oliveira

Michele Munk

\section{Resumo}

A percepção de imagem corporal e da beleza exercem grande influência na construção da identidade do sujeito e, na adolescência, essa questão tornase mais relevante, uma vez que nesta fase ocorrem várias mudanças físicas e sociais na vida dos indivíduos. Os números crescentes de casos de transtornos alimentares e as buscas por cirurgias estéticas apontam para a necessidade de discutir os conceitos de beleza e os padrões estéticos entre jovens e adolescentes. Nesse contexto, os licenciandos em Biologia da Universidade Federal de Juiz de Fora (UFJF), vinculados ao Programa Institucional de Iniciação à Docência (PIBID) elaboraram uma prática pedagógica a fim de identificar o papel social na construção de conceitos relacionados à beleza. Os dados foram coletados em turmas do $1^{\circ}$ Ano do Ensino médio de uma Escola Pública Estadual do município de Juiz de Fora - MG. Os resultados indicam que as percepções de beleza envolvem diferentes fatores, entre eles o favorecimento de características associadas a pele branca, bem como da valorização de bens materiais, tais como objetos de marca. Os resultados deste trabalho auxiliam na compreensão de como os parâmetros sociais e as mídias influenciam a percepção de beleza entre os adolescentes.

Palavras-chave: Adolescência; Beleza; Ensino de Ciências; Mídias. 


\section{PIBID teaching experiences: what is beautiful for you?}

Lara Casarim Leite

Vanessa das Graças Pereira de Souza

Lucas Rieger de Oliveira

Michele Munk

\section{Abstract}

The perception of body image and beauty exert a great influence on the construction of the subject's identity and, in adolescence, this issue becomes more relevant, since at this moments ever al physical and social changes occur in the life of individuals. The increasing numbers of cases of eating disorders and the search for aesthetic surgery point to the need to discuss the concepts of beauty and aesthetic standards among adolescents and young people. In this context, the Biology graduates of the Federal University of Juiz de Fora (UFJF), linked to the Institutional Program for Initiation to Teaching (PIBID), developed a pedagogical practice in order to identify the social role in the construction of concepts related to beauty. The data were collected in classes of the 1st Year of High School of a State Public School in the city of Juiz de Fora - MG. The results indicate that beauty perceptions involve different factors, among them the favoring of characteristics associated with white skin, as well as the valuation of material goods, such as branded objects. The results of this study help to understand how the social parameters and the media influence the perception of beauty among adolescents.

Keywords: Adolescence; Beauty; Science teaching; Media. 


\section{Introdução}

A palavra ou termo "beleza" está relacionado à um fenômeno muito discutido entre diversos seguimentos. Originalmente, a "beleza" ou a "estética" manifestou-se principalmente na área da filosofia. Uma abordagem desse termo é encontrada na antiguidade em Platão (WEISS; KARGER, 2011). Na filosofia dos tempos modernos, Immanuel Kant discute extensivamente em sua obra "The Critique of Judgment" o conceito de estética, e nesta compreende-se a beleza como uma expressão externa da moralidade interior (WEISS; KARGER, 2011).

No contexto histórico a padronização da beleza ou "rotulação" do que é considerado belo está presente em diversos períodos sempre se moldando de acordo com o contexto social econômico, histórico e com o local. Ao longo dos séculos, o conceito de beleza foi se modificando, adquirindo novas tendências, novos ideais e estabelecendo critérios que podem considerar algo belo ou não. Indubitavelmente, as condições financeiras depositam um fator preponderante no estabelecimento de certos critérios de beleza (SANT'ANNA, 2014). No Egito Antigo a nobreza apresentava a beleza vinculada com a riqueza de bens materiais, principalmente pelo acesso a itens de higiene pessoal, óleos aromáticos, maquiagens e tecidos, itens que não eram conferidos aos mais pobres (DANGELO, 2001). Por outro lado, na Grécia antiga, o corpo começa a ser cultuado como ideal de beleza. Aqueles que tinham condições de ir para a escola, podiam realizar competições de Educação Física nos famosos ginásios gregos. Aqueles, indivíduos mais fortes e definidos, no entanto, se destacavam entre os demais. A arte produzida na época pode auxiliar a visualização deste contexto, uma vez que foram produzidas com esculturas de corpos perfeitamente definidos refletindo no padrão de beleza da época. Esse pioneirismo grego gerou um marco na história o que permitiu atravessar os séculos e encorajar o Império Romano a treinar seus soldados de forma a deixá-los com a aparência atlética e com boa saúde (DANGELO, 2001).

Posteriormente, na Idade Média, o ideal de beleza mudou de maneira significante. Com a forte influência da Igreja Católica, o cuidado com o corpo foi deixado de lado, uma vez que se acreditava que era considerado um ato de heresia (SOUZA, 2004). As obras de arte mais uma vez podem auxiliar na contextualização deste padrão, uma vez que a maioria das pinturas escondem os corpos nos permitindo observar apenas os trejeitos faciais (SOUZA, 2004). Nessa época também, aos poucos os hábitos de higiene, anteriormente utilizados, foram abolidos. Este fato, possivelmente ajudou a contribuir com a disseminação de várias doenças que assolaram a Europa nesta época como sarampo, cólera, varíola, peste bubônica, hanseníase entre outras (DANGELO, 2001).

Outra mudança brusca é observada nos séculos XVIII e XIX, após a Revolução Industrial, onde corpos avantajados eram mais valorizados, principalmente pelas classes ricas 
(FREITAS et al., 2010). Com a Revolução Industrial, a ruptura entre as classes sociais menos favorecidas ficou evidente, onde as pessoas mais pobres eram mais magras pois comiam menos e trabalhavam mais enquanto os mais nobres e alguns burgueses poderiam gozar de certas regalias e se fartarem de alimentos as vezes privilegiados (SANT'ANNA, 2014). Isso retrata como a questão financeira é um fator determinante nos critérios de beleza da sociedade.

$\mathrm{Na}$ sociedade atual, considerando desde a segunda metade do século XX até os dias de hoje, observa-se grandes mudanças ao longo das décadas (SANT'ANNA, 2014). Contudo, é possível observar também o que há de comum entre os padrões. A partir da Segunda Guerra Mundial, a procura e a preocupação com a moda se intensificou em todas as camadas da sociedade, dos mais ricos aos mais pobres. É o que destaca Lipovetsky (1999), para o autor, o acesso aos recursos da moda tornou-se uma exigência de massa a partir deste momento, um cenário onde os consumidores valorizam as novidades do mercado, e que, a cada dia mostra que o novo de hoje, será esquecido ou ultrapassado no futuro.

Este século, ainda teve como aliado os grandes avanços tecnológicos, como o surgimento da televisão e dos recursos digitais, da intensa globalização que aumenta a cada dia, ou seja, a crescente mídia se desenvolveu ao longo das décadas e carregou consigo as tendências e padrões de beleza que iam se atualizando de uma maneira mais intensa (TORRI et al., 2007). Essa tendência se torna mais alarmante com o surgimento de novos produtos que, aliado ao incentivo ao consumo, marketings abusivos e anúncios chamativos, coloca em evidência a indústria da moda e de cosméticos que se destaca cada vez mais no cenário econômico que bate seus recordes de produção todos os anos (DE ARAUJO, 2018).

Antigamente, o padrão de beleza, aquilo que estava na moda ou apenas o que era considerado bonito e valorizado, se restringia apenas a uma certa localidade, cultura ou período (CASTRO, 2003). Atualmente, com a globalização, as pessoas têm o acesso à informação a apenas um clique de distância, e, dessa maneira os padrões de beleza romperam quase todas as fronteiras e pôde acessar e conquistar qualquer pessoa no mundo (SANT'ANNA, 2014).

O conceito de beleza e demais questões que envolvem a supervalorização do corpo humano passou por diversas transformações no decorrer da história, mas todas as mudanças sempre consideraram que a beleza era determinada principalmente pelo meio social, sendo reproduzido e produzido por determinados grupos, em lugares e momentos históricos específicos (SPINK; MENEGON, 1999). Nancy Etcoff (1999) discorre em seu livro sobre possíveis determinantes genéticos que estariam relacionados à essa sensibilidade humana para com a beleza física, sendo, portanto, reflexo para uma aptidão adaptativa. Coelho e Severiano (2007) destacam que o capitalismo começa a moldar um ser humano considerado um indivíduo biopsicossocial, seguindo os parâmetros estudados por Erikson (1987) e que ISSN 2526-2882 
complementam a teoria psicossexual de Freud. Esse novo conceito lança uma ruptura com padrões circulantes na filosofia, economia e sociologia da sociedade, e a partir do momento que se focaliza o ser humano em problemas egocêntricos e de identidade, caracterizando, assim, esta fase da psicanálise como a época da "Psicologia do Ego" (HALL et. al., 2000). Ainda sobre as influências desse novo enfoque no estudo psicanalítico, Erikson (1987) trata sobre o "ego plural”, fator fundamental para análise e formação da identidade de uma sociedade, sendo uma caracterização do desenvolvimento social considerando sempre o contexto histórico e cultural.

Do ponto de vista psicológico ressalta-se o Efeito Halo, fenômeno estudado inicialmente por Edward L. Thorndike, em 1920, referente à "tendência habitual das pessoas para avaliar indivíduos atraentes mais favoravelmente em seus traços de personalidade ou características do que aqueles que são menos atraentes" (STANDING, 2004, p. 451). O Efeito Halo é conhecido popularmente como "o que é bonito, é bom", refletindo diretamente nos julgamentos feitos pela sociedade e muitas vezes impostos pelos meios midiáticos. O efeito Halo também está presente em inúmeras formas no espaço escolar, destacando-se a relação entre aluno e professor, uma vez que os alunos são sujeitos de julgamento pelos educandos. Por exemplo, um docente ao observar o estudante que possui bom comportamento durante suas aulas pode enquadrá-lo na categoria de bom aluno que alcance boas notas, sem que o mesmo esteja apto nesse quesito. Quando esse fenômeno ocorre é possível que o aluno ainda saia prejudicado por ter sido pré-julgado, tendo comportamentos e retornos mal avaliados pelo docente (RASMUSSEN, 2008). Vaz e Nasser (2018) alertam para que haja sempre uma visão positivista na avaliação escolar, para que se possa pre-valer das noções de neutralidade, justiça e precisão as quais os estudantes são submetidos. Walter Mischel, autor de O teste de Marshmallow, diz:

\begin{abstract}
Descobertas recentes contradizem a suposição clássica intuitiva dos traços psicológicos, de ampla aceitação, de que pessoas são altamente coerentes ou consistentes em muitos tipos diferentes de situações. Na verdade, o que é estável e consistente é o padrão distintivo se-então de cada indivíduo, que nos ajuda a prever não só quanto cada pessoa apresentará de certa característica comportamental, mas também quando e onde ela se comportará dessa maneira (MISCHEL, p.167, 2016).
\end{abstract}

David Epstein, autor do livro “The Sports Gene”, ressalta que manter-se atualizado com temas importantes nas notícias é uma ótima maneira de criar um Efeito halo inicial positivo (EPSTEIN, 2016). Se essa mesma linha de pensamento for transposta para o consumo midiático entre crianças e adolescentes, pode-se dizer que aqueles que acompanham as tendências musicais, gestuais, modais e de demais aspectos destacados socialmente tendem a adquirir uma imagem mais positiva perante os demais.

ISSN 2526-2882

$$
19 *
$$




\section{A influência da mídia na percepção de beleza entre os adolescentes}

Atualmente as mídias de massa desempenham papel fundamental na internalização do que é beleza, representando geralmente, um mundo harmônico e idealizado, transmitindo e reforçando cada vez mais a ideia da perfeição (KNOPP, 2008). De acordo com Posch (2009, p. 140), o culto da beleza alcançou hoje todas as características de um boom tecnológico, baseado na mídia de massa. A beleza “ideal” é difundida por meio do cinema, séries televisivas, quadrinhos, reality shows, revistas ou imagens publicitárias. A influência das mídias de massa, além de contribuir para a percepção dos ideais de atratividade, gera o conflito entre o corpo real e ideal, estimulando muitas vezes a busca pelo padrão estético perfeito através de meios extremos, que envolvem dietas arriscadas, cirurgias plásticas, que comprometem à saúde física e mental (RIBEIRO; SILVA; KRUSE, 2009).

Entre os adolescentes, a influência midiática sobre padrões de beleza torna-se ainda mais preocupante, principalmente pela adolescência ser caracterizada como a fase de construção da identidade do sujeito. De acordo com Martins et al., (2010, p.20) na adolescência, os sujeitos estão mais susceptíveis as pressões exercidas pelo meio em que estão inseridos, estas, são advindas principalmente dos pais, amigos e meios de comunicação em geral.

Aberastury; Knobel (1977), ao falar sobre a adolescência, indica que há intensa influência do sociocultural em suas manifestações específicas, favorecendo ou dificultando esse estágio de transição. Nesse período da vida, o jovem é forçado a abandonar a imagem da criança, para poder abrir caminho para o futuro de sua vida adulta. É por isso que é considerado um estágio de transição entre a puberdade e a vida adulta. Neste momento, ocorrem várias mudanças, que permitem à criança integrar o mundo adulto. Então, é uma busca constante por identidade adulta, tomando os elementos oferecidos pelo ambiente social em que está imerso.

Durante o período de adolescência, o jovem busca constantemente sua identidade que lhe proporcione segurança e alta estima. Este é um dos modos que o adolescente utiliza para formar sua própria identidade. Sternbach (2006) traz que toda mudança sociocultural produz inegavelmente fortes mudanças na produção da subjetividade dos sujeitos, é por isso que os adolescentes hoje estão longe de serem adolescentes de outros tempos, e os últimos com adolescentes de épocas anteriores e sucessivas.

$\mathrm{Na}$ adolescência, o corpo adolescente é vigorosamente investido de discurso social (ROTHER, 2006). Em busca de uma identificação, o adolescente levará, ainda que transitoriamente ou não, os modelos difundidos pelo contexto cultural em que está imerso. $\mathrm{O}$ atual ideal de beleza estética e corporal, difundido principalmente pelas mídias de massa, gira em torno de um corpo esbelto e estilizado. Esses modelos oferecidos massivamente são 
utilizados pelos adolescentes como dispositivos propícios à identificação. Os modelos publicitários correspondem aos modelos exemplares de serem imitados, são mostradas aquelas mulheres esbeltas e estilizadas de corpos ideais, com uma vida de sucesso, sem preocupações ou fracassos. O adolescente, assim como toda a sociedade com que vive num determinado espaço sociocultural, deve lidar com os modelos de corpos ideais que lhe são impostos. Essa cultura, manipula o adolescente, indicando como devem ser, agir e vestir.

\section{A insatisfação da imagem corporal entre adolescentes brasileiros}

A definição de imagem corporal passa por diferentes construções que envolvem questões sentimentais, reflexivas e ações em relação ao próprio corpo e com o corpo do outro (SLADE, 1994). A insatisfação com a imagem corporal é um distúrbio que pode ser avaliado pela discrepância entre a imagem corporal real e a idealizada (SATO et al., 2010; THOMPSON; VAN DEN BERG, 2002).

Estudos apontam que a internalização de padrões estéticos considerados “ideais", ou seja, a incorporação inconsciente de determinadas concepções, que levam o indivíduo a alterações atitudinais e comportamentais, é um importante contribuinte da insatisfação corporal (CARVALHO, 2016). Os resultados da insatisfação corporal na adolescência são muitos, destacando-se os distúrbios alimentares e a busca por procedimentos estéticos a fim de alcançar a estética desejada.

O Brasil está entre os países que lideram o número de procedimentos estéticos, junto a países como Estados Unidos, Japão, México e Itália. De acordo com o relatório da International Society of Aesthetic Plastic Surgery (Isaps), de 2017, o Brasil ocupa o segundo lugar na realização de procedimentos cirúrgicos estéticos, perdendo somente para os Estados Unidos da América (EUA) (ISAPS, 2017). Entre os jovens os números são alarmantes, de acordo com o professor Jayme Farina Junior, chefe da Divisão de Cirurgia Plástica do Hospital das Clínicas da Faculdade de Medicina de Ribeirão Preto (HCFMRP) da USP, em 2017 foram realizadas cerca de 90 mil cirurgias estéticas em adolescentes, o que faz com que o país lidere o ranking desse tipo de cirurgia (USP, 2018). Para o professor, alguns desses jovens não aceitam essas mudanças e isso, somado muitas vezes à obesidade, acaba afetando a autoestima.

Os dados sobre transtornos alimentares indicam que os números têm crescido nas últimas décadas, sendo atualmente caracterizado como um grave problema de saúde pública (COSTA; VASCONCELOS; PERES, 2010). O culto a magreza, que influencia principalmente mulheres jovens, faz com que seja cada vez mais frequente a insatisfação corporal e a ocorrência de distúrbios alimentares, tais como bulimia e anorexia (ALVES; VASCONCELOS; CALVO E NEVES, 2008). Segundo Niemeyer e Kruse (2008, p.459) “a incidência dos transtornos alimentares tem maior prevalência entre os adolescentes”.

ISSN 2526-2882

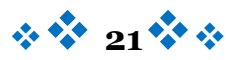


Estudos epidemiológicos recentes sobre transtornos alimentares na América Latina evidenciou uma predominância combinada de 0,1\% para anorexia nervosa, 1,16\% para bulimia nervosa e 3,53\% para transtorno da compulsão alimentar periódica no geral, população acima de 10 anos (KOLAR et al., 2016).

Diante dessa problemática, justifica-se a preocupação e necessidade da discussão sobre padrões estéticos com adolescentes.

\section{O PIBID}

O Programa Institucional de Bolsas de Iniciação à Docência (PIBID) é um programa criado pela Coordenação de Aperfeiçoamento de Pessoal de Nível Superior (CAPES) junto ao Ministério da Educação (MEC)que busca incentivar alunos dos cursos de licenciatura a desenvolver habilidades relacionada a prática de ensino. O projeto permite a vivência do bolsista na realidade escolar por meio de atividades que fazem um elo entre a teoria e a prática de modo a permitir uma formação inicial docente diferenciada. Ademais, o projeto supre algumas lacunas existentes no currículo dos cursos de licenciatura através de incentivos à pesquisa e a formação docente reflexiva.

Na Universidade Federal de Juiz de Fora o projeto PIBID teve início em 2009. Atualmente o programa conta com 22 subáreas que compreendem: Artes, Biologia, Ciências Ciclo 1, Ciências Ciclo 2, Ciências Sociais, Educação Física Presencial, Física - EAD, Educação Física - EAD, Enfermagem, Ensino Religioso, Filosofia, Física Presencial, Geografia, Informática - EAD, Letras Espanhol, Letras Inglês, Letras Português, Matemática Presencial, Matemática - EAD, Pedagogia, Química Presencial e Química - EAD. O número de escolas públicas participantes do projeto alcança, em média, 30 escolas (PIBID, 2019).

Desde 2009, o PIBID Biologia desenvolve atividades diferenciadas nas escolas públicas da região de Juiz de Fora. As atividades são voltadas para o ensino de Ciências e Biologia de modo investigativo e contextual, buscando formação reflexiva, considerando que o objeto de reflexão é tudo aquilo que se relaciona com a ação do professor durante o ato educativo articulado. Dentre as atividades está o desenvolvimento de práticas educativas que estimulem a criatividade e reflexão crítica do estudante, elaboração de experiências metodológicas com caráter investigativo e que considere aspectos tecnológicos e sociais, bem como práticas docentes de caráter inovador e interdisciplinar.

A fim de fornecer instrumentos reflexivos aos alunos, os licenciandos da Universidade Federal de Juiz de Fora (UFJF), vinculados ao PIBID, no âmbito do subprojeto Biologia voltado a alunos de ensino médio da rede Estadual de ensino em Juiz de Fora, os bolsistas de iniciação à docência desenvolveram uma prática pedagógica objetivando problematizar a construção dos conceitos padronizados de beleza. Portanto, os objetivos deste trabalho estão voltados para 
implementação e melhoramentos de práticas pedagógicas que busquem desconstruir a relação entre boa forma e o status social, ou seja, o padrão de beleza institucionalizado, na medida em que induzem ao uso de técnicas e produtos de preços elevados para a obtenção de um corpo magro, bonito e saudável (FLOR, 2009). Este trabalho busca ainda, compreender a relação da construção social e cultural, bem como do universo simbólico e material na formação de identidade pessoal e percepção de beleza entre os adolescentes.

\section{Metodologia}

A proposta pedagógica foi desenvolvida pelos bolsistas do PIBID, subárea Biologia, da UFJF. A atividade foi realizada em duas turmas do $1^{\mathrm{o}}$ ao $3^{\mathrm{o}}$ ano do Ensino Médio da Escola Estadual Fernando Lobo, localizada na cidade de Juiz de Fora, Minas Gerais. A atividade abrangeu um total de 205 (duzentos e cinco) alunos. A proposta surgiu a partir de problematizações acerca da influência midiática sobre a construção e percepção do jovem no âmbito social.

Como recurso foram utilizados bonecos esquemáticos do contorno do corpo humano conforme indicado na figura 1. Os esquemas não distinguiam cor, sexo ou qualquer característica física. No ato da entrega dos bonecos, os bolsistas de iniciação à docência orientaram os alunos sobre o que deveria ser feito: um desenho simples, daquilo que eles consideram bonito em uma pessoa. Sem mais especificações. Houve ainda a informação de que não seria permitido trocas de sugestões entre eles ou quaisquer formas de agressão verbal ou moral a respeito do desenho do outro.

Figura 1: Modelo utilizado no desenvolvimento da prática

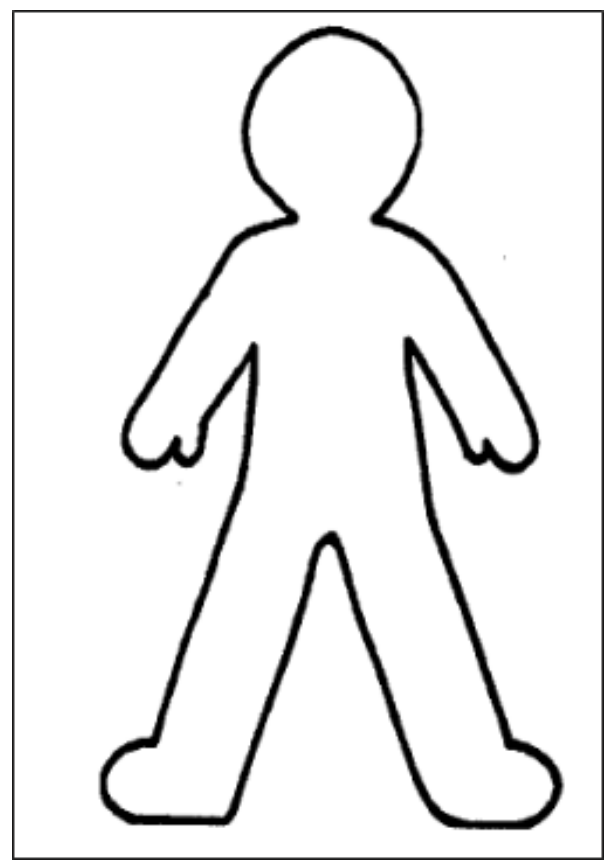

Fonte: Google Imagens.

ISSN 2526-2882

$* 23 *$ 


\section{Resultados e Discussão}

Analisando o gráfico 1, observa-se que dos 105alunos que realizaram a atividade, 47 desenharam em seus moldes padrões que caracterizam homens, e 58 desenharam mulheres. Portanto, 55,23\% dos desenhos foram relacionados a padrões femininos de beleza. De acordo com BADINTER et al., (1993) a beleza geralmente está associada à promoção da atratividade física a fim da obtenção de benefícios sociais. A atratividade física, sendo vista como o objeto central da feminilidade, justifica que práticas de beleza sejam na maioria das vezes associadas ao gênero feminino.

Estes resultados permitem uma reflexão sobre como práticas de beleza são manipuladas na caracterização de papéis sociais e na construção das identidades de gênero.

Gráfico 1: Sexo representado pelos estudantes

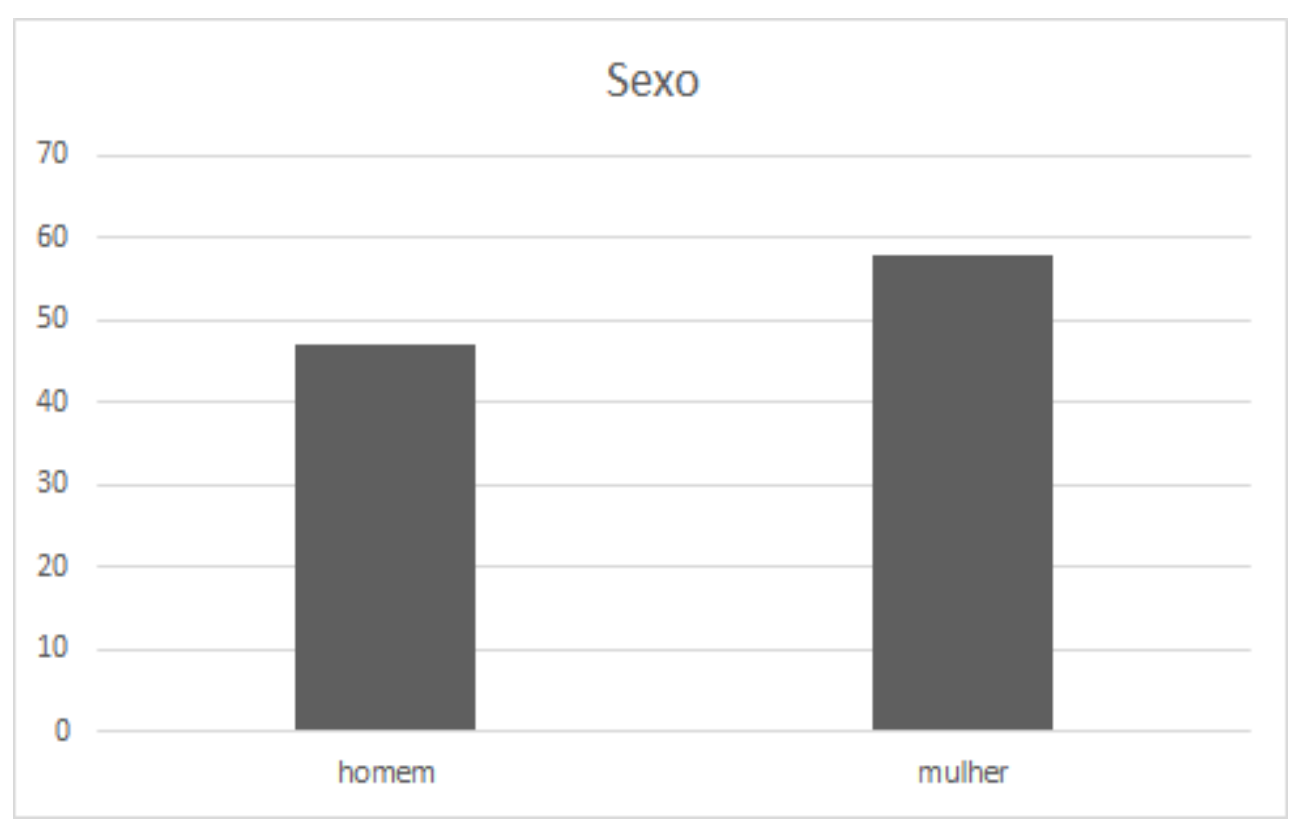

Fonte: arquivo pessoal

Dos desenhos que se referem ao sexo feminino, observou-se que na categoria "cor de pele" $85,70 \%$ de desenhos representavam mulheres brancas e apenas $14,30 \%$ representavam mulheres negras, com relação aos desenhos que faziam referência ao sexo masculino, 90\% dos desenhos representavam homens brancos, e apenas 10\% homens negros (Gráfico 2A). Na categoria "tipos de cabelos", 85,70\% dos estudantes desenharam mulheres de cabelo liso, e 14,28\% desenharam mulheres com cabelo crespo, ao passo que 36,64\% dos estudantes desenharam homens de cabelo liso, e 63,36\% desenharam homens de cabelo crespo (Gráfico 2B). 
Por meio das preferências estéticas, percebe-se que a brancura é tomada como referencial de beleza entre os adolescentes. Esta tendência também é encontrada em outros trabalhos (DOMINGUES, 2002; FRANÇA, 2011; POOLE, 2013). Santos (2015) discute extensivamente a forma que as mídias de massa legitimam padrões de beleza associados a tons de brancura, neste trabalho, ficou evidente com a mídia brasileira dá pouca ênfase e representatividade aos não brancos, sobretudo os pretos.

A mídia, assumindo um papel de grande influência sobre os adolescentes, e tendo destaque na determinação do belo e do não-belo, auxilia na menor visibilidade da estética negra, ao optar pela valorização da estética branca/europeia e contribui por legitimar a supremacia branca nos ditames dos padrões pré-determinados de beleza e na construção da estética socialmente aceita.

Gráfico 2: Cor da pele e tipo de cabelo representados pelos estudantes
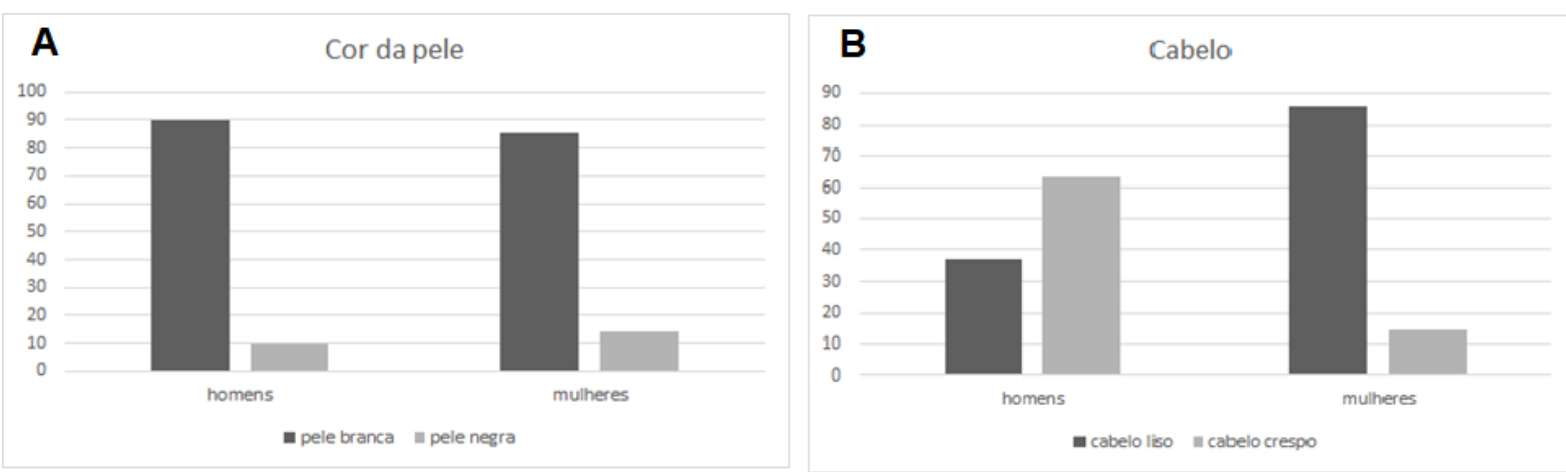

Fonte: Arquivo pessoal

Por último, na categoria "Roupagem", 21,42\% desenharam mulheres usando roupas de grifes famosas e $\mathbf{2 7 , 2 7 \%}$ desenharam homens usando roupas de grifes famosas e/ou caras (Gráfico 3).

De acordo com Pierre Bordieu (1998, p. 63) "O status consiste na possibilidade de desfrutar certos bens simbólicos, pois estes determinam de certo modo a classe social que o indivíduo ocupa”. Segundo o autor, os bens simbólicos são instrumentos de conhecimento, comunicação e integração social e podem ser apropriados pelo conjunto de um grupo ou produzidos por especialistas, determinando o status (Figura 3). Notadamente, esses pertences simbólicos podem ser exemplificados por alimentos consumidos, tipos de leitura, carros e demais mensagens presentes na mídia (SROUR, 1987). 
Gráfico 3: Referência à marcas famosas

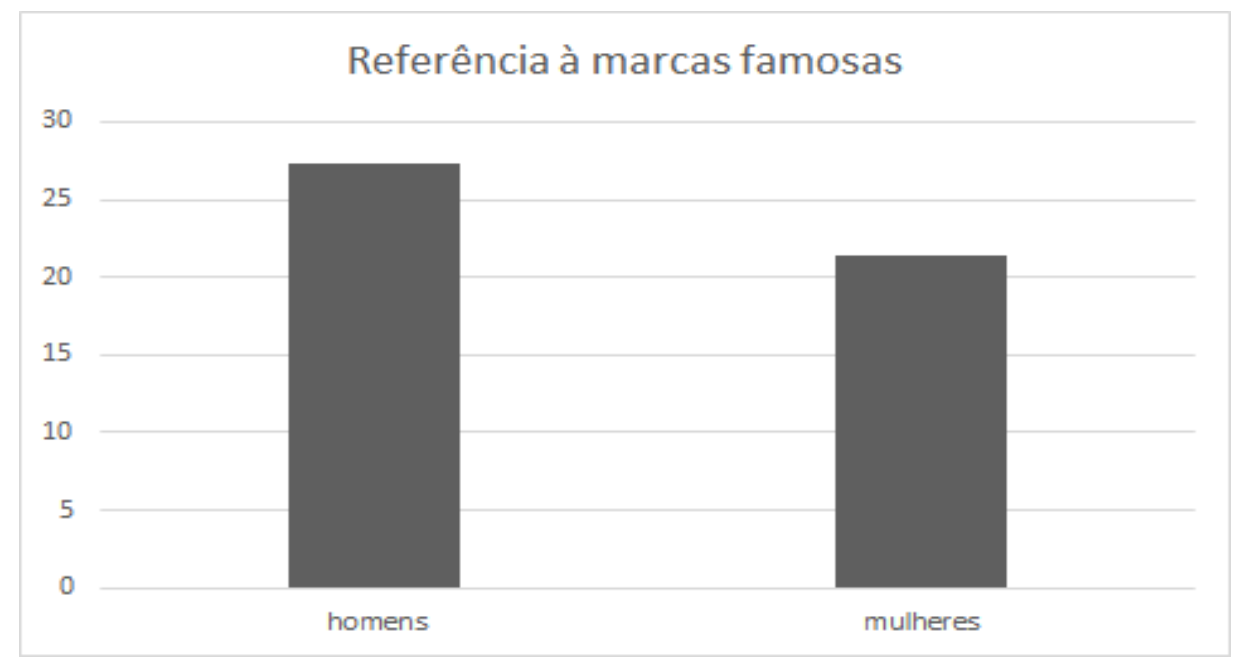

Fonte: Arquivo pessoal

Durante a aplicação da atividade os bolsistas se depararam com situações que exigiam bastante discernimento, sensibilidade e embasamento teórico. Em determinado momento alunos questionavam a finalidade da atividade, e era nessa hora que a atividade ganhava novas conotações e os alunos eram estimulados a exercitarem a reflexão e construírem sob a orientação dos bolsistas as respostas para as indagações. A análise do corpo é um componente elementar para a compreensão das estruturas sociais e suas relações de poder (FOUCAULT, 1987).

Alguns alunos percebiam que o objetivo da atividade era fazer com que os mesmos revissem os conceitos de beleza que carregavam e que fizessem uma análise sobre o que há de bonito em si e no outro. O uso de redes sociais e sua influência na determinação de conceitos estéticos são fenômenos ainda recentes, e tem sido alvo de diferentes estudos objetivando compreender os efeitos à sua exposição (VERMELHO; VELHO; BERTONCELLO, 2015). Sabese que a imagem corporal é influenciada por vários fatores, sendo os principais: os pais, os amigos e a mídia (THOMPSON; COOVERT; STORMER, 1999). Esta última, sinônimo de "meios de comunicação social", é a mais persuasiva das influências.

Alguns materiais produzidos se destacaram pela riqueza de informações e por sua relevância de conteúdo. Estes desenhos acabaram se tornando alvo de discussões produtivas nas reuniões do PIBID Biologia após a aplicação da prática, fazendo com que a atividade se tornasse muito mais relevante no ponto de vista acadêmico de produções do subprojeto no âmbito da Universidade.

No que tange os padrões de beleza impostos ao público feminino, não há dúvida que a ênfase de toda a busca pela beleza ideal envolve o desejo de magreza, tornando este um sonho praticamente inalcançável para muitas mulheres, somente sendo possível atingi-los através de ISSN 2526-2882 
meios não considerados saudáveis (HARISSON; CANTOR, 1997). Na figura 3, cuja autora, quando questionada informalmente durante a aplicação da atividade, relatou ter se desenhado da maneira como gostaria de ser, despertou o interesse tanto dos bolsistas quanto de alguns colegas de turma; talvez tenha sido este o desenho mais emblemático dentre todos os analisados. Nele a autora exemplifica, em todas as minúcias, como ela gostaria de ser, mas destacando no final que ela não era nada daquilo que desenhou. Acrescentou, ainda, a forte influência que recebia de determinadas digitais influencers que acompanhava em redes sociais e também em realitys shows. Dito isto, foi levantado um questionamento a toda turma: quem conhecia aquelas digitais influencers? Praticamente todos os alunos conheciam ou acompanhavam pessoas na internet que, segundo eles, "ditam as modas do momento". Díaz (1998) e Tocantins (2015) abordam a vasta gama de influência que os meios midiáticos podem se expressar e introduzir seus conteúdos. Essa estreita relação entre os adolescentes e a mídia, com suas estipulações envolvendo os ideais de magreza e afins, contribui de maneira significativa para os mais elevados índices de insatisfação corporal e desordens alimentares (SMOLAK; LEVINE, 1996).

Com relação aos homens adolescentes, há evidências de que o ideal corporal começou a mudar por volta de 1980, também devido a influência das mídias, com os corpos masculinos excedendo o limite da masculinidade com o uso de esteroides anabólicos (HOFFMANN; AMSTAD, 1994). Na figura 3, a autora destaca que o que lhe chama a atenção em um menino são, principalmente, as roupas de marca que ele está usando. A presença de adornos como piercings e brincos também se fazem presentes na representação. Sobre isso, Lipovetsky, em entrevista, ressalta:

Antes de mais nada, a estetização do mundo acompanha a própria história da humanidade. Desde a pré-história tínhamos formas de estetização, como as pinturas faciais, as bijuterias, os diferentes adereços. A novidade é que a estetização hoje é conduzida pelo capitalismo pós-fordista, que não se contenta em produzir produtos funcionais, mas investe em produtos de moda para vender mais, qualquer que seja a área. No passado, um par de óculos era apenas uma órtese para enxergar melhor. Hoje é um acessório de moda. O mesmo raciocínio vale para o automóvel, para os móveis, para tudo. Estamos na época do capitalismo artista, que incorpora a dimensão artística em todos os domínios da indústria (LIPOVETSKY, 2015).

Hoffman-Muller e Amstad (1994) observaram em seu estudo que a imensa maioria dos homens estão satisfeitos com seu corpo, enquanto metade das mulheres se encontravam insatisfeitas com seu próprio corpo. Durante a adolescência, as mulheres de fato apresentam um grau de insatisfação quanto ao próprio corpo maior do que do homens (FEINGOLD; MAZZELLA, 1998).

ISSN 2526-2882 
A influência midiática sobre o uso de roupas relacionadas a marcas famosas também recai ao uso de uniformes. A figura 2 mostra um desenho em que se destaca um casaco de moletom com um único símbolo referente à uma escola particular do município de Juiz de Fora, que fica próxima à escola pública estadual na qual aplicamos a prática. Quando questionada sobre seu desenho, a autora do mesmo disse que, para ela, a beleza é poder "desfilar por aí com um uniforme de uma escola chique e cara, e postar fotos usando-o" (Larissa, Declaração dia 10 de maio, 2017). Segundo Covre (2015, p. 6), "a ostentação pode ser encarada como uma ode à riqueza, um comportamento, um estilo de vida, onde o indivíduo concentra no luxo e poder, o complemento imagético para conduzi-lo ao caminho da felicidade, a realização do sonho e à autoestima”. Essa é exatamente a visão que a estudante tem perante o uso de informes de escolas particulares, pois o mesmo carrega consigo toda a carga de influências que essa adolescência recebe e que almeja para si.

Figura 2: uniforme equipe

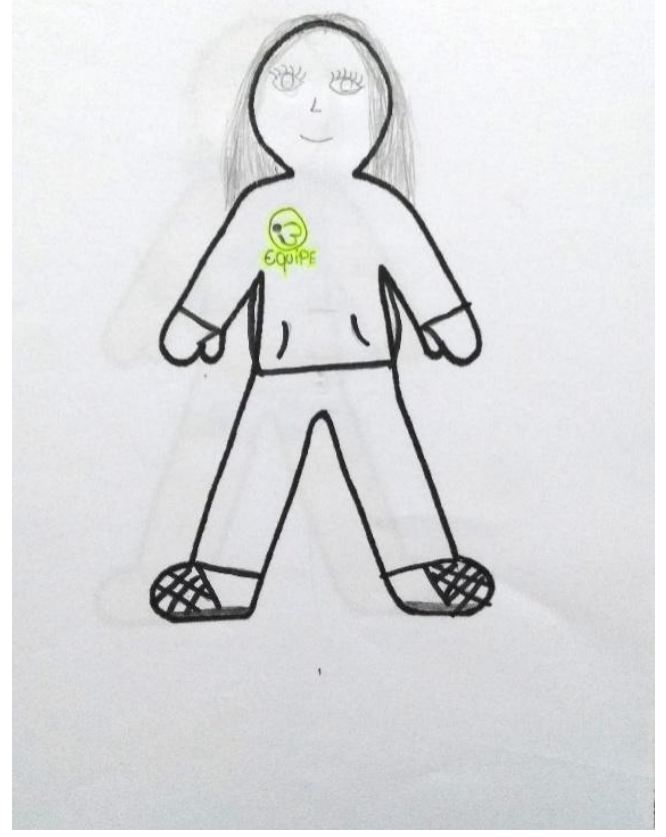

Fonte: Arquivo pessoal
Figura 3: menino com roupas de marca

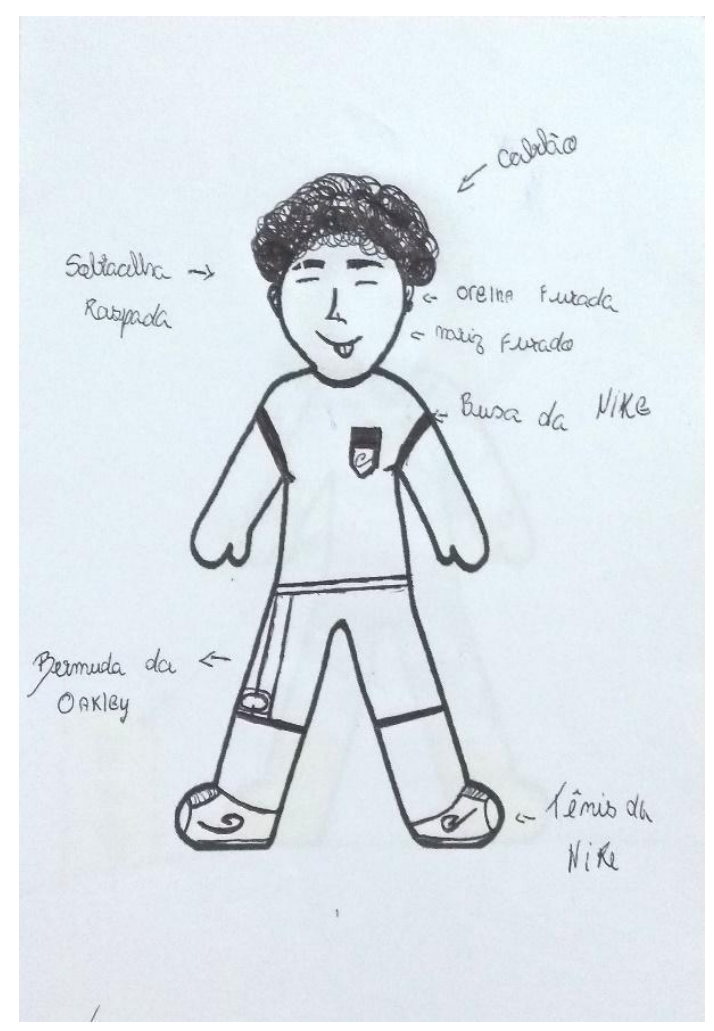

Fonte: Arquivo pessoal 
Figura 4: menina com vários adereços de marcas

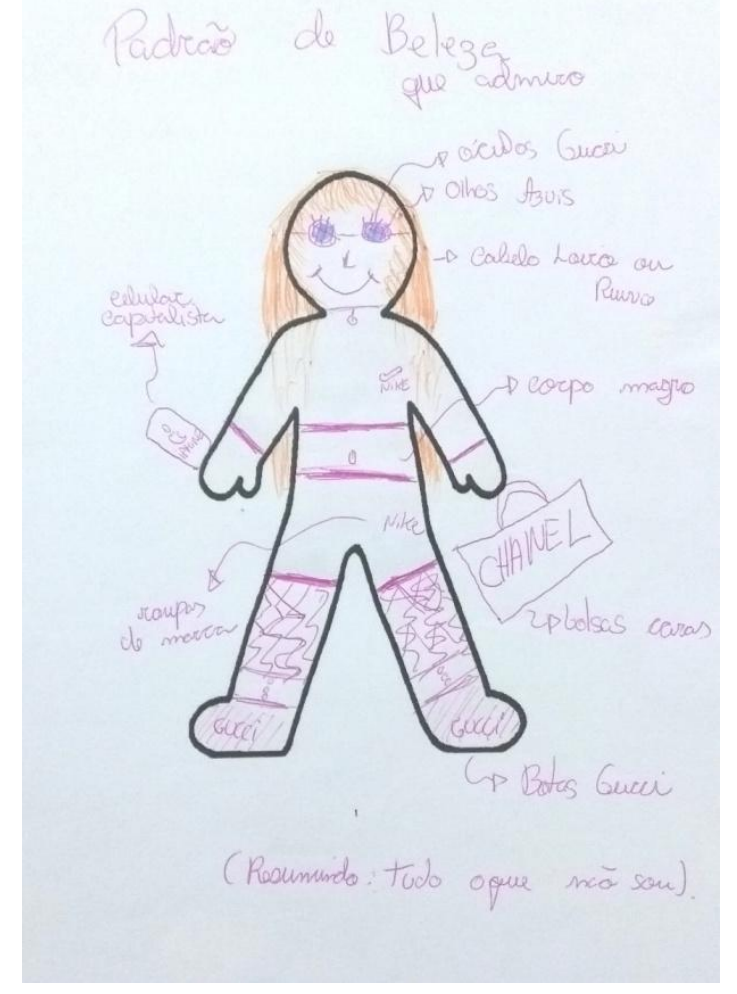

Fonte: Arquivo pessoal

\section{Conclusão}

No decorrer dos períodos históricos ocorreram muitas transformações nas formas de percepção de beleza na humanidade. Atualmente, o conceito de beleza está associado a diferentes fatores, destacando-se o aspecto econômico, corroborando com os achados do presente estudo (FRY, 2002; MALYSSE, 2002; NOVAES, 2006). Considerando que a beleza é uma construção social, investigar os padrões estéticos socialmente construídos e reproduzidos na escola, auxilia na compreensão de certas exclusões existentes devido a imposição de parâmetros os quais são utilizados como "filtro", tanto para se ver belo quanto para atribuir beleza ou feiura a determinado indivíduo.

O presente estudo demonstrou que a mídia, por meio de seu discurso e propagandas publicitarias, impõe aquilo que deve ser visto como belo, saudável e desejável, sendo todos estes fatores relacionados intrinsecamente ao status social, desejado pela maioria dos jovens. Esse discurso pode levar as pessoas a acreditarem que não serão felizes se não tiverem uma aparência que esteja de acordo com este padrão de beleza (JORGE, 2006). Nesse sentido, cabe os professores de ciências e biologia a elaboração de propostas metodológicas voltadas a esses jovens estudantes que modifiquem esse cenário. Isso é urgente uma vez que além de envolverem questões atuais, há pouco material sobre esse tema direcionado para os adultos, sendo o foco principal, a juventude estudantil. 
Este trabalho contribui no campo educacional, demonstrando que atividades reflexivas podem ser uma ferramenta eficiente, dinâmica e atrativa para auxiliar no processo de construção do conhecimento. Adicionalmente, a proposta de trabalhar metodologias alternativas no contexto do PIBID Biologia colaborou na formação inicial de professores e no desenvolvimento de práticas inovadoras para a melhoria do ensino de Biologia no Ensino Médio.

\section{Referências}

ABERASTURY, A.; KNOBEL, M. La adolescencia normal: Un enfoque psicoanalítico. $1^{\mathrm{a}}$ ed. México: Paidós educador, 2004.

ADORNO, T.; HORKHEIMER, M. Dialética do esclarecimento. Rio de Janeiro: Zahar, 1985 .

AlVES, E.; VASCONCELOS, F. A. G.; CALVO, M. C. M.; E NEVES, J. Prevalência de sintomas de anorexia nervosa e insatisfação com a imagem corporal em adolescentes do sexo feminino do Município de Florianópolis, Santa Catarina, Brasil. Caderno de Saúde Pública, v.24, n.3, p. 503-512. 2008.

BADINTER, E. XY Sobre a identidade masculina. $2^{\text {a }}$ ed. Rio de Janeiro: Ed. Nova Fronteira, 1993.

BOURDIEU, P. La distinción: critérios y bases sociales del gusto. Madrid: Taurus, 1988.

CARVALHO, P. H. B. Adaptação e avaliação do modelo teórico de influência dos três fatores de imagem corporal para jovens brasileiros. Tese - Universidade Federal de Juiz de Fora. Processos Psicossociais em Saúde. Juiz de Fora. 2016.

CASTRO, A. L. de. Culto ao corpo e sociedade: mídia, estilos de vida e cultura de consumo. São Paulo: Annablume: Fapesp, 2003.

COSTA L. C. F.; VASCONCELOS F. A. G.; PERES K. G. Influence of biological, social and psychological factor sonab normal eating attitudes among female university students in Brazil. Journal Health Popul Nutricional. v. 2, n. 28, p. 173-181. 2010.

COVRE, P. O. A Cultura da Ostentação: Uma análise da grande mídia e Institutos de Pesquisa. Monografia. USP, Novembro, 2015.

D’ANGELO, J.; LOTZ, S.; DEITZ, SALLIE. Fundamentos de estética 1: orientações e negócios. $10^{\mathrm{a}}$ ed. São Paulo, 2001.

DE ARAUJO, T.S.; FILHO, V. C. B.; GUBERT, F. A.; ALMEIDA, P.C.; MARTINS, M.C.; CARVALHO, Q.G.S.; COSTA, A.C.P.J.; VIEIRA, N.F.C. Factors associated with body image perception among Brazilian students from low human 
development index areas. The Journal of School Nursing, v. 34, n. 6, p. 449-457. 2018.

DOMINGUES, P.J. Negros de almabranca? A ideologia do branqueamento no interior da comunidade negra em São Paulo, 1915-193o. Estudos AfroAsiáticos. v. 24, n.3, p.563-599, 2002.

EPSTEIN, D. A psychological trick to get anyone to like you. Disponível em: http://www.psychtronics.com/2016/o8/a-psychological-trick-to-get-anyone-tolike-you.html. Acesso em: 12 jan. 2019.

ERIKSON, E. H. Infância e Sociedade. $2^{a}$ ed. Rio de Janeiro: Zahar editores, 1987.

ERIKSON, E. H.; ERIKSON, J. O ciclo da vida completo. Porto Alegre: Artes Médicas, 1998.

ETCOFF, N. A lei do mais belo: a ciência da beleza. Rio de Janeiro: Objetiva, 1999.

FEINGOLD, A.; MAZZELLA, R. Gender differences in bodyimage are increasing. Psychological Science. 1998; 9, 190 - 195.

FLOR, G. Corpo, Mídia E Status Social: reflexões sobre os padrões de beleza. Rev. Estud. Comun., Curitiba, v. 10, n. 23, p. 267-274, 2009.

FOUCAULT, M. Vigiar e punir. Petrópolis: Vozes, 1987.

FRANÇA, D.X. Concepções sobre o próprio e outro grupo: Um estudo sobre estereótipos em crianças índias, mulatas, negras e brancas.In: E.M., Techio, M.E.O., Lima (Org). Cultura e produção das diferenças: estereótipos no Brasil, Espanha e Portugal. Brasília: Technopolitik. 2011.

FRY, P. Estética e política: relações entre "raça", publicidade e produção da beleza no Brasil. In: Goldenberg \& et. al. (Org) Nu \& Vestido: dez antropólogos revelam a cultura do corpo carioca, Rio de Janeiro: Record. 2002.

GOLDEMBERG, M. A civilização das formas: o corpo como valor. Nu e vestido. Rio de Janeiro: Record, 2002. p. 139-188.

HOFFMANN-MULLER, B.; AMSTAD, H. Bodyimage, weight and eating behavior in adolescents. Schweizerische Rundschau für Medizin Praxis. v. 83, n. 48, p. 13361342. 1994 .

HALL, C. et. Alli. Teorias da Personalidade. Porto Alegre: Artes Médicas, 2000.

HARRISON K.; CANTOR J. The relations hip between media consumption and eating disorders. Journal of Communication Disordersl. v. 47, n. 1, p. 40-67. 1997.

HORNSTEIN, R. M. C. Adolescencias: Trayectorias Turbulentas. Buenos Aires: Paidós, 2006.

JORGE, S. Ditadura da Beleza: uma visão subjetiva. Disponível em: http://www.psicologia.pt/artigos/ver_opiniao.php?codigo=AOPoo68. Acesso em: ISSN 2526-2882 
23 jan. 2019.

KNOPP, G. A influência da mídia e da indústria da beleza na cultura de corpolatria e na moral da aparência na sociedade contemporânea. In: IV Encontro de Estudos Multidisciplinares em Cultura (ENECULT). Salvador: UFBA, 2008.

KOLAR D.R.; RODRIGUEZ D. L.; CHAMS M.M.; HOEK H.W. Epidemiology of eating disorders in Latin America: a systematic review and meta-analysis. CurrOpinPsychiatry. V.29, n.1, p.363-71.2016.

LIPOVETSKY, G. O Império do Efêmero: a moda e seu destino nas sociedades modernas. Tradução Maria Lucia Machado. São Paulo: Companhia das Letras, 1999.

LIPOVETSKY, G. O essencial é a embalagem. Disponível em: https://alias.estadao.com.br/noticias/geral,o-essencial-e-a-embalagem,1672132. Acesso em: 23 jan. 2019.

MALYSSE, E. Em busca dos (H) alteres-ego: olhares franceses nos bastidores da corpolatria carioca. In: Goldenberg (et. al.) $\mathrm{Nu} \&$ Vestido: dez antropólogos revelam a cultura do corpo carioca, Rio de Janeiro: Record. 2002.

MARTINS, C. R.; PELEGRINI A.; MATHEUS, S. C.; PETROSKI, E.L. Insatisfação com a imagem corporal e sua relação com estado nutricional, adiposidade corporal e sintomas de anorexia e bulimia em adolescentes. Revista de Psiquiatria do Rio Grande do Sul. v. 32, n.1, p.19-23. 2010.

MISCHEL, W. O teste do marshmallow: Por que a força de vontade é a chave do sucesso. $1^{\text {a }}$ ed. Rio de Janeiro: Editora Objetiva, 2016.

NIEMEYER, F.; KRUSE, M. H. L. Constituindo sujeitos anoréxicos: discursos da Revista Capricho. Texto e Contexto - Enfermagem, Florianópolis. v. 17, n. 3, p. 457-465. 2008.

NOVAES, J.V. O intolerável peso da feiura: sobre as mulheres e seus corpos. Rio de Janeiro: Ed. PUC - Rio: Garamond, 2006.

PIBID. Programa Institucional de Bolsas de Iniciação a Docência. Universidade Federal de Juiz de Fora. Disponível em: http://www.ufjf.br/pibid/home/703-2/ . Acesso em: o6 jan. 2019.

POOLE, MAURITA N. "Brown Skin Is Halfis Beauty": Representations of Beauty and the Construction of Race in Contemporary Cairo. Tese - Emory U. Anthropologia, US. 2018.

POSCH, W. Projekt Körper. Wie der Kult um die Schönheit unser Lebenprägt. Frankfurt/Main: Campus-Verlag, 2009. 
RABELLO, E.T.; PASSOS, J. S. Erikson e a teoria psicossocial do desenvolvimento. Disponível em: <http://www.josesilveira.com> Acesso em: 07 jan. 2019.

RASMUSSEN, K. (2008). Halo Effect. In N. J. Salkind \& K. Rasmussen (Eds.), Encyclopedia of Educational Psychology, Volume 1. Thousand Oaks, CA: Sage Publications, Inc.

RIBEIRO, R. G.; SILVA K. S.; KRUSE M. H. L. O corpo ideal: a pedagogia da mídia. Revista Gaúcha de Enfermagem. v.30, n.1, p. 71-76. 2009.

ROTHER HORNSTEIN, M. C. Entre desencantos, apremios e ilusiones: barajar y dar de nuevo. In: ROTHER HORNSTEIN, M. C. (Org.). Adolescencias: trayectorias turbulentas. $1^{\mathrm{a}}$ ed. Buenos Aires: Paidós, 2006. p. 51-79.

SANT'ANNA, D. B. História da beleza no Brasil. São Paulo: Contexto, 2014.

SANTOS, E. V. A. Influência da Cor da Pele nas Representações Sociais Sobre a Beleza e Feiura. Dissertação - Universidade Federal de Sergipe. Centro de Educação e Ciências Humanas. Sergipe. 2015.

SATO, P. M.; TIMERMAN, F.; FABBRI, A. D.; SCAGLIUSI, F. B.; KOTAIT, M. S. A imagem corporal nos transtornos alimentares: como o terapeuta nutricional pode contribuir para o tratamento. In: Alvarenga MS, Scagliusi FB, Philippi ST. Nutrição e transtornos alimentares: avaliação e tratamento. $1^{\mathrm{a}}$ ed. São Paulo: Manole; 2010. p. 475-97.

SMOLAK, L.; LEVINE, M. P. Adolescent transitions and the development of eating problems. In: The development psychopathology of eating disorders: Implications for research, prevention, and treatment. Mahwah, New Jersey: Erbaum, p. 207 - 233, 1996.

SOUZA, A. F. C. O percurso dos sentidos sobre a beleza através dos séculos: uma análise discursiva. Dissertação (mestrado) - Universidade Estadual de Campinas, Instituto de Estudos da Linguagem. Campinas, SP. p. 224, 2004.

SROUR, R. H. Classes, regimes, ideologias. São Paulo: Ática, 1987.

STANDING, L. G. Halo Effect. In M. S. Lewis-Black, A. Bryman, \& T. F. Liao (Eds.), The SAGE Encyclopedia of Social Science Research Methods, Volume 1. Thousand Oaks, CA: SAGE Publications, Inc, 2004.

STERNBACH, S. Adolescencias, tiempo y cuerpoenlaculturaactual. In: ROTHER HORNSTEIN, M. C. (Org.). Adolescencias: trayectorias turbulentas. $1^{\mathrm{a}}$ ed. Buenos Aires: Paidós, 2006. p. 51-79.

TALAMONE, R. Brasil lidera ranking de cirurgia plástica entre jovens. (produzido pela locutora Mel Vieira e pela estagiária Giovanna Grepi, da Rádio USP Ribeirão, com trabalhos técnicos de Mariovaldo Avelino e Luiz Fontana. Apresentação de Mel

ISSN 2526-2882 
Vieira e direção de Rosemeire Soares Talamone; escritos de Thainan Honorato). Disponível em: jornal.usp.br/?p=149532. Acesso em: 02 fev. 2019.

THOMPSON, J. K.; SMOLAK, L. Bodyimage, eatingdisorders, and obesity in youth: Assessment, prevention, and treatment. Washington, DC: American Psychological Association, 2001.

THOMPSON, J. K.; VAN DEN BERG, P. Measuring body image attitudes among adolescents and adults. In: Cash TF, Pruzinsky T, editors. Bodyimage: a hand book of theory, research and clinical practice. New York: The Guilford Press; 2002. p. 14254 .

THOMPSON, J. K.; COOVERT, M. D.; STORMER., S. M. Body image, social comparison, and eating disturbance: A covariance structure modeling investigation. International Journal of Eating Disorders, 26(1), 43-51. 1999.

TORRI, G.; BASSANI, J.; VAZ, A. Dor e tecnificação no contemporâneo culto do ao corpo. Pensar a Prática, 10(2), 93-105. 2007.

VAZ, R. F. N.; NASSER, L. Um Estudo Sobre O Efeito Halo Na Correção De Provas. Sociedade Brasileira de Educação Matemática - Regional Rio de Janeiro. Rio de Janeiro, de 16 a 18 de maio de 2018.

VERMELHO, S. C.; VELHO, A. P. M.; BERTONCELLO, V. Sobre o conceito de redes sociais e seus pesquisadores. Educ Pesqui. v.41, n.4, p. 863-881. 2015.

WEISS, H.; KARGER, I. L. Schönheit: Die Versprechen der Beauty-Industrie. $2^{\mathrm{a}}$ ed. Munique: Deuticke Verlag, 2011.

\section{Agradecimentos}

Agradecemos ao projeto PIBID, por ter contribuído de forma tão grandiosa com nosso crescimento pessoal e profissional. Aos nossos colegas atuantes no projeto, Amanda Cristina, Arthur Ponte, Márcia Kelly, Laura Pires, Laura Martins, Milla Mariano, Letícia Furtado e Letícia Gonelli, que durante todo o tempo nos deram apoio e sugestões quanto ao nosso trabalho. À orientadora do subprojeto Biologia, Michele Munk, por toda sua dedicação em orientar-nos e pelo incentivo constante. Às professoras supervisoras Lucimar, Raquel e Marina, que sempre acreditaram no nosso potencial e nunca negaram uma palavra de incentivo. Às escolas participantes, que abriram suas portas às nossas ideias. A Universidade Federal de Juiz de Fora, por contribuir com a nossa formação docente. Por fim, manifestamos aqui nossa gratidão a todos os alunos que nos receberam de braços abertos para a realização das atividades, reafirmando sempre que nossa escolha de seguir na área docente nunca será em vão. Nosso muito obrigado.

ISSN 2526-2882 


\section{Biografia Resumida}

Lara Casarim Leite: Licencianda em Ciências Biológicas pela Universidade Federal de Juiz de Fora; Membro do Grupo de Pesquisa e Prática de Educação de Jovens e Adultos da Universidade Federal de Juiz de Fora; cooperadora do projeto "Laboratório na Rede”, vinculado ao Departamento de Ciências Naturais do Colégio de Aplicação João XXIII/UFJF.

Link do lattes: http://lattes.cnpq.br/4458808890910093

e-mail: laracasarim@hotmail.com

Vanessa das Graças Pereira de Souza: Licenciada em Ciências Biológicas pela Universidade Federal de Juiz de Fora; Mestranda em Ciências Biológicas - Genética e Biotecnologia (PPGCBio) pela Universidade Federal de Juiz de Fora.

Link do lattes: http://lattes.cnpq.br/7960453586286498

e-mail: vanessagpds@gmail.com

Lucas Rieger de Oliveira: Licenciado em Ciências Biológicas pela Universidade Federal de Juiz de Fora; Diretor-Presidente da Biociclos Empresa de Consultoria e Projetos em Meio Ambiente, Empresa Jr do Curso de Ciências Biológicas da UFJF; Professor Bolsista do Colégio de Aplicação João XXIII pelo Programa de Iniciação a Docência da Educação de Jovens e Adultos.

Link do lattes: http://lattes.cnpq.br/6382317433492368

e-mail: lucas.rieger2014@gmail.com

Michele Munk: Atualmente é Professora Adjunta do Departamento de Biologia da Universidade Federal de Juiz de Fora (UFJF), coordenadora da área de Biologia/Ciências do Programa Institucional de Bolsas de Iniciação à Docência (PIBID)-CAPES da UFJF e orientadora do Programa de Pós-Graduação em Ensino de Biologia em Rede Nacional (PROFBIO-CAPES, UFJF/UFMG).

Link do lattes: http://lattes.cnpq.br/8094404295191170

e-mail: michele.munk@ufjf.edu.br

ISSN 2526-2882 